\title{
OPERATION FOR CORRECTION OF PARALYTIC EXTERNAL (LATERAL) RECTUS PALSY*
}

BX

\section{J. P. Spencer Wailker}

HOVE

THE following account of an operation for the correction of palsy of the external rectus in two children may be of interest.

Case 1.-This child, a girl of nearly 4 years of age, had palsy of the right external rectus. The history suggested a birth injury. The right eye was amblyopic, and the following glasses were prescribed, R.E. plus 2.0D. Sph., L.E. plus $1.50 \mathrm{D}$. Sph. Her vision with glasses tested with the " $E$ " was $R$.E. less than $6 / 60$ L.E. 6/12. The right eye was unable to fix. The objective angle of convergence, was approximately 45 degrees. . Eight months later the objective angle of convergence with the glasses was the same, namely plus 45 degrees.

The operation was performed the next day. Eight days later the angle on the synoptophore was minus 5 degrees, thus showing a slight tendency to diverge, but on the ninth day the angle was plus 3 , measured when she was looking straight ahead. The angle, however, was very variable. On the sixteenth day the angle was plus 5 with glasses. There was also a beginning of the power to abduct the right eye about this time, and by the twenty-first day this had become much stronger. On the twentyfifth day the objective angle on the synoptophore was plus 5 degrees with glasses, and plus 10 without, and she appeared to have the power to abduct the right eye fully. In fact she was so proud of this accomplishment, that she would turn her eyes rapidly to the right and left for the entertainment of anyone who would watch her.

The reason for doing this operation was primarily " cosmetic," and this desirable result has been obtained, but it will be interesting to see if it will now be possible to improve the amblyopia, and even perhaps, when she is older, to get binocular vision.

Case 2.-This girl is 5 years old, and has had palsy of the left external rectus since birth, but, as the left eye is not amblyopic, she turned the head over the left shoulder. The objective angle of convergence was 20 degrees, and the angle increased to 35 degrees when looking to the left. Her synoptophore readings three weeks after the operation were "Angle on synoptophore minus 10 degrees (divergent) fixing with the right eye, and minus 15 fixing with the left. Projection is true. The fusion angle is

* Received for publication, February 9, 1495. 
minus $10 \mathrm{~L} / \mathrm{R} 3$. No amplitude at present. She is sometimes binocular, but has no power of convergence yet." The next day the readings were the same as the above, but she began to show some signs of convergence on the synoptophore. The next day she was able to adduct 15 degrees. A week later the subjective angle on the synoptophore was, fixing with right eye, minus 5 looking straight ahead, 0 looking to the left; fixing with left eye minus 10 looking straight ahead, 0 looking to the left. The fusion angle was now minus 5 degrees. Thus the over-correction was steadily being reduced, and the power to adduct beginning to develop.

The head tilt was greatly improved immediately after the operation, but as the left sterno-mastoid seemed stiff, and there was still some slight postural torticollis, she was sent to the Physio-therapeutic Department of the Royal Sussex County Hospital for treatment.

Unfortunately I have not been able to follow this case further as she has returned to her home in London, but I have asked one of the London Ophthalmic Hospitals to take charge of her. This operation was done primarily to correct the torticollis, and it would appear that she should with orthoptic training and physio-therapy make a good recovery.

\section{Operation}

In both cases the same operation was performed, and so only one need be described. This operation was in every respect but one similar to that described by W. B. Lancaster in Berens' "The Eye and its Diseases," and also by Magnus in the Brit. Jl. Ophthal. in May, 1944. The internal rectus was first recessed, being stitched to the sclera slightly anterior to the equator. The performance of this recession is where this operation differs from that described by Lancaster. The external rectus was next exposed and shortened by cutting it through about $2 \mathrm{~mm}$. from its insertion. The outer third of the superior and also of the inferior rectus were next prepared in the manner described by Lancaster, and their free ends stitched to the stump of the insertion of the external rectus. The shortened external rectus was then stitched to the sclera anteriorly to its original insertion, thus performing a resection and advancement of the external rectus. The conjunctival incision was closed. There is no need to give further details as the operation has been clearly described by Lancaster, who ends his accounts by saying "the results are excellent."

My reasons. for reporting these two cases are, first they support his conclusion, and secondly I consider that the synoptophore readings taken before and after the operations are of interest, and 
may be a guide in other cases. They show what a large angle can thus be overcome, and the almost daily improvement obtained by orthoptic training after the operation. My only regret is that I did not have-a photograph of the children taken before the operation, so that I could have another taken afterwards. In his paper of May, 1944, J. A. Magnu's states that his case had little or no power of abduction after the operation, but in my first case the child has developed this power, and it seems possible that the second may also do' so. , As regards the advisability of recessing the internal rectus in these cases, this point must be left to the individual judgment of the particular surgeon, who should base his conclusions on the synoptophore readings taken before the operation. For myself, I am far from convinced that an advancement should be ever performed without a recession of the opposing muscle, though the recession may have to be only part of the way between the insertion and the equator.

\section{REFERENCES}

LANCASTER, W. B.- "Operations on ocular muscles." Chapter LXV, p. 1148. (Berens' Eye and its Diseases).

Magnus, J.-Trans. Ophthal. Soc. U.K., Vol. LXII, p. 318, 1942 ; Brit. Jl. Ophthal., Vol. XXVIII, p. 241, May, 1944.

PAYNe, B. F (New York).-Amer. Jl. Ophthal., Vol. XXVI, p. 390.

Stallard, H. B.-Abstract on the above, Brit. Jl. Ophthal , Vol. XXVII, p. 564, No. 12, December, 1943.

\section{PENICILLIN IN OPHTHALMOLOGY*}

With special reference to its application in treatment outside hospital

BY

T. G. Wynne Parry, G. C. Laszlo

and

J. L. Penistan, M.D., M.R.C.P.

PATHOLOGIST, E.M.S. LABORATORY

FROM THE FYE DEPARTMENT, CAERNARVONSHIRE AND ANGLESEY INFIRMARY, BANGOR

THE scope of penicillin in the treatment of diseases of the eye has been widely discussed in recent papers by Milner (1944), Robson (1944), Florey and Florey (1943) in this country, and von Salmann $(1943,1944)$ and others in America. It is our purpose here to record our experiences in its use which has been largely directed towards ascertaining its value in self administration by patients

- Received for publication, July 3, 1945. 